\title{
Article
}

\section{Politics ahead of patients: The battle between medical and chiropractic professional associations over the inclusion of chiropractic in the American Medicare System}

\author{
Young, Kenneth \\ Available at http://clok.uclan.ac.uk/32735/ \\ Young, Kenneth ORCID: 0000-0001-8837-7977 (2019) Politics ahead of \\ patients: The battle between medical and chiropractic professional \\ associations over the inclusion of chiropractic in the American Medicare \\ System. Canadian Bulletin of Medical History, 36 (2). pp. 381-412. ISSN 0823- \\ 2105
}

It is advisable to refer to the publisher's version if you intend to cite from the work. http://dx.doi.org/10.3138/cbmh.330-022019

For more information about UCLan's research in this area go to

http://www.uclan.ac.uk/researchgroups/ and search for <name of research Group>.

For information about Research generally at UCLan please go to http://www.uclan.ac.uk/research/

All outputs in CLoK are protected by Intellectual Property Rights law, including Copyright law. Copyright, IPR and Moral Rights for the works on this site are retained by the individual authors and/or other copyright owners. Terms and conditions for use of this material are defined in the policies page. 
1 Politics ahead of patients: the battle between medical and chiropractic professional associations over the inclusion of chiropractic in the American Medicare system

\section{ABSTRACT}

Healthcare professions struggling for legitimacy, recognition, and market share can

6 become disoriented to their priorities. Healthcare practitioners are expected to put the

7 interests of patients first. Professional associations represent the interests of their members.

8 So when a professional association is comprised of healthcare practitioners, its interests may

9 differ from those of patients, creating a conflict for members. In addition, sometimes

10 practitioners' perspectives may be altered by indoctrination to a belief system, or

11 misinformation, so that a practitioner could be confused as to the reality of patient needs.

12 Politicians, in attempting to find expedient compromise, can value a "win" in the legislative

13 arena over the effects of that legislation. These forces all figure into the events that led to the

14 acceptance of chiropractic into the American Medicare system. Two healthcare systems in a

15 political fight lost sight of their main purpose: to provide care to patients without doing harm.

\section{KEYWORDS}


The classical version of the Hippocratic Oath contains a well-known sentiment: "First do no harm." The oath set forth an idea that has become integral to healthcare professions, that the interests of patients supersede those of the practitioners. Medical physicians, chiropractors and others continue to administer a version of it upon graduation. ${ }^{2}$ Yet, in struggling for legitimacy, recognition, and market share in a fee-for-service structure, professions can become disoriented to their priorities. Professional associations, which represent the interests of their members, who in this case are health practitioners, find that sometimes those interests conflict with the interests of their members' patients, or the public at large. In addition, sometimes practitioners' perspectives may be altered by indoctrination to a belief system, or misinformation, so that a practitioner could be confused as to the reality of patient needs. These forces all figure into the events leading to the acceptance of chiropractic into the American Medicare system. I believe this paper is the first scholarly work do explore these events. Themes of professionalization, professional identity, and legitimacy figure prominently. Chiropractic sought legitimation through wider acceptance by policymakers and other healthcare providers, and they wanted a share of the aged care market. Organized medicine sought to protect the public from what they considered a danger to public health, and they fought to control government reimbursement services. Legislators acted as they usually do, by weighing public opinion and lobbyist influence, then taking the expedient action. In the end, chiropractic was accepted into Medicare, but not to the degree they had hoped. Organized medicine inserted a "poisoned pill" into the legislation at the last minute, hoping to derail the entire process, but it did not work as anticipated. Legislators scored a victory, though, by passing a popular bill expanding Medicare with much more than just the addition of chiropractic. Richard Nixon, who was helped to re-election in 1972 by its 
new uniform system of well-earned benefits for older Americans, the blind and the disabled." All participants in the chiropractic portion of the Medicare expansion process focused on their own interests rather than those of their patients and some patients were harmed, physically, mentally, and/or financially.

The [REDACTED] University Human Research Ethics Committee approved this research (approval number 2012/152). This paper draws on a variety of primary sources of information, including interviews with several key figures involved in the events described herein as well as their contemporaneous writings in professional publications, the Congressional Record, and one audio recording. I also utilized secondary sources like books, newspapers and journal articles accessed in public and private archives.

The history of health care in the United States of America (USA) involves disparate forces, including government, insurance companies, pharmaceutical and medical device manufacturers, doctors' groups, and professional associations. Emphasis on health promotion and consumerism have also affected policy decisions. There has been no unified national policy on healthcare in the USA, but rather many policies on various aspects of healthcare.

60 This patchwork has resulted in entrepreneurship and research that has offered exceptional care to some, but not all, and it carries a massive economic cost. Healthcare spending in the USA is more than twice per capita the amount in the UK, and the overall outcomes are not as good. All the American government provider systems arose after a private insurance system was well-established, and were shaped to support that private system, with the fee-for-service model that was economically advantageous for doctors, hospitals, and medical groups. One of the most influential organizations in consolidating this structure was the American

67 Medical Association (AMA) which had successfully opposed all forms of nationalized 68 healthcare. ${ }^{4}$ 
70 American healthcare. ${ }^{5}$ In the mid- $19^{\text {th }}$ Century, a wide variety of "irregular" health practitioners competed on a market basis with "regular" or orthodox physicians for patients. Many medical treatments at this time were either without effect other than placebo; others were simply dangerous. ${ }^{6}$ This disorganized environment led a group of physicians to draft a set of ethical and educational standards for practitioners. The document became the 1847 Code of Medical Ethics of the AMA. It was a public proclamation that formed the basis of the fiduciary relationship between patients and practitioners. In exchange for the responsibility of ensuring trust in the uniform standards of skills and behaviour for physicians as well as acting in the public interest, it claimed autonomy for the profession. ${ }^{7}$ But Sociologist Tracey Adams cites the fluidity in the definition of 'public interest' and notes changes in response to public demand over time. She also acknowledges incomplete understanding as to the true motivations of professions invoking the concept of public interest. Whether used in earnest or cynically to gain power and status, the social contract made the professional association more powerful. ${ }^{8}$ Physicians were allowed to determine standards of skills and behaviour that one must demonstrate in order to become and remain a physician, and even the scope of what is considered medical practice. The 1847 pact formed the base on which were built the ideas of self-regulation and monopoly power which would eventually impact all alternative systems, including chiropractic, once it was founded in 1895. Sociologist and authority on professionalism Eliot Freidson noted that exclusivity of membership and special expertise supported by professional associations helped create public acceptance of a profession's self-regulation. ${ }^{9}$ The social pact could only be subsequently altered from within the association, and transgressors could be banished and left without its protections. $^{10}$

Alternative healthcare systems, which by definition were outside medical associations like the AMA, were viewed as rivals, marginalized with rhetoric, disparaging labels, and 
later, legal action. Chiropractors were only one group among many, including osteopaths, homeopaths and Christian Scientists, who were called "quacks" and denigrated in various publications. ${ }^{11}$ Beginning in 1870 , organized medicine, led by the AMA, began to use its power in order to suppress these alternative systems. Legislators were lobbied to pass laws regulating the practice of medicine. Medicine became defined as provision of any type of healthcare by any type of practitioner. In 1906, the AMA was able to ensure that licensure was granted only to graduates of schools approved by their Council of Medical Education. ${ }^{12}$ Thus, alternative practitioners could be prosecuted for practicing medicine without a licence. This was the beginning of a hegemonic process continued by the AMA for decades. Professional autonomy is often moderated by government regulation. But calls for oversight have often come from within a profession. Regulation brings legitimation and additional enforcement mechanisms for exclusivity of access. That is, the public assumes that regulated practitioners are competent, and the profession can limit entry to its ranks, which can help ensure competence of practitioners. It can also decrease competition. This has been seen frequently with healthcare, where medical professional associations and the state work together, limiting the ability of alternative practitioners like homeopaths, botanical healers, apothecaries and others to provide services designated as "medical."13 anthropologist Hans Baer characterizes the hegemony of the AMA as a class issue, involving

114 a coalition of interests with a common goal: "The emerging alliance around the turn of the

115 century between the AMA, which consisted primarily of elite practitioners and medical researchers based in prestigious universities and the industrial capitalist class, ultimately

117 permitted biomedicine to establish political, economic, and ideological dominance over rival 118 medical systems."14

119 Scientific advancement, such as with inoculations, meant that patients became less 
likely to understand how treatments worked, yet nonetheless were able to benefit from those treatments. Matthew K. Wynia, long-time Director of the AMA Institute for Ethics and

122 Center for Patient Safety, posits that over time this led to pride, paternalism, loss of empathy and reduced standards of customer service in the medical profession. The growth of scientific medicine also achieved so many successes in cures and treatments that arguments against medical control of healthcare seemed almost ridiculous. ${ }^{15}$ Hubris and power combined to lead to a sense of entitlement. The AMA began to believe its judgment was infallible, and that the state was its enforcement arm.

The hegemonic process helped lead to the disappearance of some alternative therapies, but many still exist. Of all the complementary and alternative (CAM) health professions, only American osteopathy took the route of eliminating its alternative practices and beliefs. This resulted in the AMA removing its cultism label from osteopathy in 1961. The AMA even extended membership to osteopaths and allopathic residency programmes accepted osteopathic graduates. But the tradeoff for osteopathy was that by the 1970s it had

134 lost its unique identity in America and was virtually indistinguishable from medicine. ${ }^{16}$

135 Several authors have touched on the chiropractic episode, but little historical analysis has been undertaken. Two contemporaneous authors and chiropractic supporters, AMA whistleblower William Trever and chiropractor Chester Wilk, adopted a position of outrage at the tactics of the medical opposition to chiropractic, and both related much first-hand

139 information in their books. Wilk later became the main plaintiff in a successful anti-trust

140 lawsuit against the AMA. ${ }^{17}$ Trever included reproductions of internal AMA and state-based medical group memos as well as correspondence with legislators. Some of these documents were also used as exhibits in Wilk's suit. But neither author related the specific details of the

143 Medicare episode. ${ }^{18}$ Peterson and Wiese in Chiropractic: An Illustrated History, sociologists 144 Holly Folk, Susan Smith-Cunnien and Walter Wardwell, and historian J. Stuart Moore only 
briefly mention Medicare in their histories. ${ }^{19}$

None of the above sources explain the legislative manoeuvring that resulted in the

147 outcome. None provide the details of how the traditional use of radiography in chiropractic enabled the AMA to develop the x-ray clause for the legislation, the mechanism by which the

149 scope of practice was limited. A brief background on the traditional chiropractic healthcare 150 paradigm is necessary for context.

\section{THE ORIGINS AND DEVELOPMENT OF CHIROPRACTIC}

Although manual manipulation of bones and joints as a healing art has existed for centuries, the particular method that came to be called chiropractic originated in the USA in 1895. For the first few decades of the its existence, chiropractic considered itself alternative rather than complementary to medicine, and some in the profession still do. The traditional chiropractic ideology or practice paradigm was a form of vitalism. Daniel David Palmer, known as D.D., was a Canadian-born merchant and self-styled "magnetic" healer living in Davenport, Iowa at that time. Palmer credited a mysterious force that he called Universal Intelligence, essentially a form of god, as responsible for life and health. This force manifested in humans as "Innate Intelligence" in the brain, and was transmitted as "nerve impulses" down the spinal column through nerves to all the organs and body parts. Therefore, if a vertebra was slightly out of place, a state he called "subluxation", it could impinge nerves, alter the flow of the impulses, and create ill health. D.D. held the opinion that $95 \%$ of

164 disease was caused by subluxated vertebrae and the remaining $5 \%$ by subluxated peripheral 165 joints, such as the elbow or ankle. ${ }^{20}$ Palmer began teaching his new theory to others almost immediately, including to his son Bartlett Joshua Palmer, known as B.J. After D.D. suddenly

167 departed Iowa for the west coast in 1902, B.J. assumed responsibility for the school his father 168 had started, asserting himself as leader of the budding profession. In 1910 he made a decision 169 that would have repercussions more than half a century later by incorporating x-ray into 
chiropractic as a way to prove subluxations. ${ }^{21}$

Through the mid- $20^{\text {th }}$ century, chiropractic took steps toward professionalization.

Kansas and North Dakota were the first states to license chiropractors and by 1963 all but two states had chiropractic legislation, although scopes of practice varied. ${ }^{22}$ The National Board of Chiropractic Examiners was established in 1961, and the Federation of Chiropractic Licensing Boards in $1968 .{ }^{23}$ The Council on Chiropractic Education, formed in 1935 by the National Chiropractic Association (forerunner to the ACA) in an effort to standardize chiropractic education, was accredited by the Department of Health, Education and Welfare in August 1972. ${ }^{24}$ Reforms led to the decline in numbers of teaching institutions from 42 in 1930, most with 18-month courses, to 15 in 1963, all with 4-year courses. These efforts seem to have been taken in a sincere effort to gain legitimacy. Donning the mantle of orthodoxy in organizational structures must also have made chiropractic more palatable by a wider swath of legislators.

Like other CAM professions, chiropractic has a schism that it has not yet reconciled. ${ }^{25}$ The two main groups of chiropractors have often been referred to as "straights" and "mixers." This division reflected an emphasis on treatments employed. Straights used manual manipulation or "adjusting" of the spine for all ailments. Mixers "adjusted" as well, but also used heat, cold, ultraviolet, massage techniques, and other ancillary measures not including drugs and surgery. In this paper, I change the focus of the division from treatment methods to aetiology of disease. Broadly, some within the profession hold to the traditional idea that subluxations are the predominant influence on health, and often radiography is considered the primary tool for detecting this "lesion." 26 This group will be referred to as traditional or vitalistic chiropractors. The other group will be referred to as biomedically-oriented chiropractors. Generally, they believe in germ theory, the utility of vaccinations, judicious use of diagnostic imaging, and other mainstream healthcare tenets. They focus on manual 
therapy for biomechanical conditions, view themselves as complementary rather than alternative, and seek integration with overarching health systems. In my opinion, it is more important to understand the paradigm a healthcare practitioner applies to health and disease than to focus on treatment methods. The overall paradigm is more revealing of a practitioner's comprehension of diagnosis, science, and evidence, and therefore gives greater insight into the differences in the chiropractic factions.

These groups do not neatly divide into the two main professional associations in the USA, the American Chiropractic Association (ACA) and International Chiropractors Association (ICA). There is overlap of health paradigm in both membership populations, although the ICA tends to have more traditionalists in its leadership and constituents, and the ACA more biomedicals. In the 1960s, the ACA had about twice as many members as the ICA. There were also "independents" who belonged to neither group, and in this group the paradigm varied as well. For purposes of this paper, the predominant paradigm of each association will be used in the understanding that uniformity of opinion did not exist, but tendencies did.

\section{THE AMA'S EFFORTS TO CONTAIN AND ELIMINATE CHIROPRACTIC}

By the 1960s, most alternative health systems in the USA had either disappeared, like Thompsonians and naprapaths, had been marginalised into insignificance like Christian Scientists and naturopaths, or been incorporated into medicine like osteopaths. Chiropractors, however, retained their independence, and had gained a small but consistent part of the healthcare market. About $10 \%$ of Americans and Canadians have used their services. ${ }^{27}$ Chiropractic became a particular target of the AMA. The AMA's methods were many and varied. They printed and distributed thousands of anti-chiropractic brochures to schools, colleges, medical practices and organizations. They sent fake prospective student applications to chiropractic colleges in order to expose weaknesses in the education system. They wrote 
letters to professional journals and popular magazines, lobbied legislators at the local, state, and federal levels to try to exclude chiropractic, and they pressured members of influential committees. $^{28}$

In 1963, the AMA formed a Committee on Quackery to "[determine] the true nature of chiropractic and its practitioners, and to inform the medical profession and the public of its findings." ${ }^{29}$ The product of this investigation was a pamphlet, entitled Chiropractic: The Unscientific Cult. In setting the tone for the Committee, the AMA House of Delegates issued the following statement: "Either the theories and practices of scientific medicine are right and those of the cultists are wrong, or the theories and practices of the cultists are right and those of scientific medicine are wrong. ${ }^{30}$ In 1967, H. Doyl Taylor, secretary of the Committee on Quackery and a leading figure in AMA efforts on chiropractic, spoke at a "quackery workshop" held at Ball State University in Indiana, framing the discussion with this statement: "As you know, [chiropractic] is a cult, about as far removed from scientific medicine, the diagnosis and treatment of human illness as it is possible to get." ${ }^{31}$ The ridiculing nature of these words de-legitimised chiropractors in the structure of the argument. It portrayed the AMA as representing the norm and chiropractic as deviant. Sociologists Yvonne Villanueva-Russell and Susan Smith-Cunnien asserted that by defining chiropractic as "deviant" and using derogatory terms like "unscientific cult," the AMA could frame itself as mainstream, reasonable, and scientific, for its own social and political benefit. ${ }^{32}$ Despite acknowledging that a variety of practice paradigms existed within chiropractic, the AMA's focus remained on the vitalistic chiropractors. ${ }^{33}$ Some of the statements by the Committee on Quackery seem political or adversarial, rather than clinically detached: "With the establishment of the Committee on Quackery, in 1964, extensive study was made to determine exactly what chiropractic is and where it is most vulnerable to public exposure." 34 Trever expresses it this way: "the Committee lacked sufficient 'scientific proof' 
245 to back their slanderous campaign., ${ }^{, 35}$ Because of the extreme measures to ensure secrecy at

246 the AMA, the totality of the information that the Committee obtained on chiropractic

247 practices is not known. ${ }^{36}$ However, the examples they cited were damning for chiropractic.

248 The pamphlet included reproductions of advertisements claiming cures for various diseases

249 including cancer and mental illness. Chiropractors were quoted making statements against the

250 utility of vaccinations. Repeatedly noted was an epistemology invoking appeal to authority;

251 the "authority" was usually either D.D. or B.J. Palmer. The Unit Plan also denigrated

252 chiropractic educational standards, which were, in fact, inferior to those of medicine. ${ }^{37}$ It

253 further stated: "The prime mission of the Committee on Quackery at its founding was to be,

254 first, the containment of chiropractic, and, ultimately, the elimination of chiropractic as a

255 health hazard." ${ }^{38}$ Part of the plan was to influence legislative bodies. ${ }^{39}$ It stated that "the

256 Medicare-Medicaid rules on chiropractic [must be] drawn as tightly as possible." ${ }^{40}$ The Unit

257 Plan described ghost-writing policy statements and distributing publications on behalf of

258 various "independent" bodies such as the American Federation of Labor-Congress of

259 Industrial Organizations (AFL-CIO) and the Consumer Federation of America in order to

260 lend the weight of ostensible support from respected organizations to their message. ${ }^{41}$ The

261 AMA sponsored multiple regional conferences called "Health Quackery - Chiropractic" over

262 a period of five years. They attempted to derail accreditation of chiropractic schools. Doctors

263 and hospitals were forbidden from granting chiropractors any privileges including receiving

264 referrals of patients for x-rays or blood tests. The Unit Plan did concede that after

265 chiropractic ceased to exist, chiropractors, with their manual skills, might be able to be retrained "to serve as another extension of the physician's hands." 42

At this point it could be argued that the AMA and other medical associations genuinely believed that they were acting in the public interest, fulfilling their fiduciary duty as they saw it, by attempting to limit public access to chiropractors, whom they viewed as 
dangerous. Their later actions became more ethically questionable.

\section{THE INCLUSION OF CHIROPRACTIC IN MEDICARE}

In 1964, Lyndon Johnson won the presidency; his agenda included improving healthcare. ${ }^{43}$ However, concessions had to be made to medical special interest groups, including coverage for physician outpatient services as well as hospital visits for both general and specialty practitioners. Physicians were given total freedom in diagnosis, treatment and prescription of medications. The fee-for-service model was retained, and people were able to see whichever doctor they wanted. ${ }^{44}$ The bill with these provisions became the first iteration of Medicare, and it passed with AMA approval in 1965, ${ }^{45}$ resulting in improved health and well-being for many people across the country. ${ }^{46}$ Medicare quickly became popular, and other health professions, including chiropractic, optometry, social work, and eight others requested inclusion. Congress opened an investigation into the possibility of expanding Medicare. ${ }^{47}$ In 1967, Wilbur Cohen, the Secretary of Health, Education, and Welfare (HEW), was tasked with undertaking the study.

The government required the health professions to provide evidence of legitimacy. The Federation of Chiropractic Licensing Boards (FCLB) oversaw chiropractic licensing. Chiropractor Richard E. Vincent represented the FCLB in testimony to the House Ways and Means Committee, assuring Congress that there were professional standards as well as a mechanism for upholding them. ${ }^{48}$ However, the assessment process turned out to be neither straightforward nor transparent. According to sociologist and HEW committee member Walter Wardwell, the report essentially had been written before the committee even met. ${ }^{49}$ He also related that pressure was applied to members of the committee to adopt the AMA position. Wardwell later revealed all the anti-chiropractic documents and verbal recommendations from AMA members that he had received as a member of the committee. ${ }^{50}$ Sociologist Catherine Biggs has indicated that in Canada, the government responded 
to the tension between the popularity of chiropractic services and the opposition of the powerful medical lobby by calling for a Royal Commission or equivalent to study the matter.

In Canada's case, the government reports provided rationales for including chiropractic in state-funded healthcare. ${ }^{51}$ Not so in the USA. The final HEW report issued 28 December 1968 recommended that chiropractic not be included in Medicare, concluding: Chiropractic theory and practice are not based upon the body of basic knowledge related to health, disease, and health care that has been widely accepted by the scientific community. Moreover, irrespective of its theory, the scope and quality of chiropractic education do not prepare the responded with a White Paper, accusing Congress of a biased process and attempting to clarify what they perceived as mischaracterizations of the profession. Congress dismissed it as invalid. ${ }^{53}$ The two main chiropractic associations, the ACA and ICA, embarked on a

310 political pressure campaign. It was comprised of three elements: working to amalgamate the two associations, letter writing to Congress, and lobbying through personal connections.

312 Being faced with a larger, better funded, and more politically connected lobbying

313 organization in the AMA, it was of paramount importance for chiropractic to present a

314 unified front to the world. In addition, experience had taught chiropractors that state and

315 federal panels insisted on a single body of representation. ACA member James Cox remembers: "I've testified in my state of Indiana before House and Senate committees. If you

317 go in there split, you know what they say: 'You get it together and then you come back.",54

318 This created the impetus to join the two chiropractic professional associations. The ICA had 319 about 4000 members. ${ }^{55}$ They were overt in their advocacy of a traditional, vitalistic view of 
chiropractic and wanted the legislation to consider only the treatment of vertebral subluxation. ${ }^{56}$ The ACA had about 7500 members, and tended to be more biomedically-

oriented. The ACA's position was that chiropractors should be reimbursed for all the services that they provided, not just for attending to vertebral subluxations. These services varied state to state, depending on the licensure regulations, but included therapeutic ultrasound, electrotherapy, massage techniques, and rehabilitation protocols. ${ }^{57}$ The ICA insisted that the ACA agree to a definition of chiropractic known as the "Chicago scope of practice." ${ }^{58}$ It focused on spinal subluxations as the cause of all disease, with radiography for subluxation detection. Contemporaneous articles in chiropractic magazines included promotion of $\mathrm{x}$-ray imaging for subluxation analysis by ICA chiropractors. For example: "It enables him to see inside and through the living body, pinpointing with accuracy, the health problem areas... This aid is necessary in visualising the misalignments of the spinal column..."59 The strength of this belief can be seen in its longevity and the language used by some of its proponents. In 1977, Leon R Coelho, chair of the ICA Radiation Control Committee and director of the Roentgenology Department of the Palmer College of Chiropractic wrote an article entitled "If spinography is dead, so is chiropractic" in an ICA publication and included the following: system, yet growing and surviving in an imperfect world. But do you know something? IT IS THE BEST OF ALL SYSTEMS OF WHICH WE ARE CONSCIOUS. HAVE FAITH IN IT, NOURISH IT, LOVE IT, because it pathological diagnosis and railed against the idea of using ionising radiation as a screening 
345 tool for all patients. ${ }^{61}$ The ICA model for the radiographic visualization of subluxations was

346 denigrated by ACA chiropractors including Joseph Howe, who noted that normal anatomical

347 asymmetry, minor variations in osseous architecture, slight changes in patient position during

348 radiography, and the physics of the x-ray beam all invalidated the idea that "subluxations"

349 could be identified and quantified on radiographs. The tiny misalignments claimed by some

350 chiropractors to be lesions causing disease were due either to illusion or imagination. ${ }^{62}$ The

351 schism in chiropractic was particularly stark on the use of the x-ray. The potential merger of

352 the two chiropractic associations failed again. ${ }^{63}$

353 The ICA and ACA submitted separate statements to the government. The ICA

354 requested reimbursement for spinal x-rays and spinal adjustments only. The ACA statement

355 acknowledged the usefulness of standard physical examination and diagnostic tests and also

356 discussed "subluxation," but as a biomechanical dysfunction, rather than a vitalistic entity,

357 and without the necessity of radiography to identify. ${ }^{64}$ The ACA statement also invoked the

358 idea of freedom of choice in health care and requested recognition of states' rights in regard

359 to scope of practice. That is, the ACA argued that Medicare legislation should reimburse for

360 whatever services chiropractors were licensed to provide in each state, rather than be limited

361 to adjusting spinal subluxations as the ICA advocated. This limit was viewed as overriding a

362 state's right to determine the scope of practice for chiropractors. ${ }^{65} \mathrm{HEW}$ denied this argument

363 in 1969, citing lack of evidence for the effectiveness of chiropractic treatment and asserting

364 that their responsibility for the "safety and welfare of beneficiaries" allowed HEW to

365 determine the services to be reimbursed. ${ }^{66}$

366 Because the two chiropractic associations portrayed chiropractic differently, the AMA

367 was able to choose a portrayal of chiropractic that could serve to bolster its position opposing

368 Medicare coverage for chiropractors. Hoyt B. Duke of the ACA recognised this, writing that

369 the rigidity of the ICA's position and the infighting that it caused were making chiropractic 
vulnerable to attack by the AMA. ${ }^{67}$ There is no indication that either the ICA or ACA were acting cynically or simply playing for power; they both sincerely believed that their position was the correct one. The ICA believed that they were preserving chiropractic more truly to the founder's ideals. The ACA was less concerned with tradition and was trying to move chiropractic into a new phase of existence, embracing a more scientific approach to healthcare.

The two chiropractic professional associations did cooperate on other lobbying efforts. David D. (Dave) Palmer, grandson of founder D.D. Palmer, was the president of the Palmer College of Chiropractic in the late 1960s and early 1970s. As such, his assent was considered necessary for consensus on any strategic chiropractic-wide project. Palmer met with ICA President William Day, ACA President Gerald Brassard, and other influential chiropractors in 1970 to discuss the "intensified Medicare-inclusion plan." ${ }^{\prime 68}$ It included an organized letter writing operation to encourage Congressional Representatives and Senators to support including chiropractic in the Medicare expansion bill. The sample letters distributed by the chiropractic associations highlighted the benefits of chiropractic and also appealed to sensitive areas in American politics: market freedom and American Exceptionalism. ${ }^{69}$ American Exceptionalism was expressed by sociologist and political theorist Seymour Lipset as: liberty, egalitarianism, individualism, populism, and laissez-faire. Lipset noted that even before the rise of the neoconservatives, which started with President Ronald Reagan, the USA had lower rates of taxation, a less developed welfare state, and fewer government-owned industries than other industrialised nations. ${ }^{70}$ The idea of freedom in the healthcare marketplace attained similar enshrinement and this was also present in the chiropractic community. ${ }^{71}$ Chiropractors argued that the AMA and government policies were restricting peoples' freedom to choose the health care provider that they desired. William Day wrote, "It is the birth-right of every American citizen to have the right to choose his own 
particular type of health care, and it is our duty to make it possible for them to have the opportunity to choose chiropractic!"72 The goal was to have 10,000 letters sent from

397 chiropractors and patients. Ultimately, at least a million letters went out. ${ }^{73}$ Because of this

398 popular support, many House Members introduced bills on the subject. Congressman Wilbur

399 Mills, who had been instrumental to the passage of Medicaid legislation, noted that this had

400 influenced the decision to include chiropractic. ${ }^{74}$ William Scott (Bill) Day was a particularly influential figure in the lobbying effort.

Day had been a Washington State Representative from 1959-1969 before being elected to the State Senate from 1969-1980. ${ }^{75}$ He was a graduate of the Palmer School (1947), and the son of two Palmer graduates. He took over the clinic in Spokane, Washington that his parents started, and his son Tim, also a Palmer graduate, has operated it since Day's death in 1984. Day helped ensure that traditional chiropractic was legislated as the scope of practice in Washington. ${ }^{76} \mathrm{He}$ also supported the traditional paradigm for chiropractic in Medicare, testifying to that effect as Legislative Chairman of the ICA in front of the Senate Finance Committee on September 16, 1970, along with other representatives of the ICA and ACA. ${ }^{77}$ Steve Renner also attended the Palmer school, and was employed in Day's clinic from 1976 - 1982. He recalled discussing the matter with Day: “[Bill] became friends with

412 Washington State's two U.S. Senators, Henry Jackson and Warren Magnuson. These two 413 were high-ranking Democrats in Congress. So because Bill was subluxation-based and his 414 connections with Jackson and Magnuson is how chiropractic became included in Medicare 415 [sic]." ${ }^{, 78}$ Richard Vincent, an ACA chiropractor and president of the FCLB at the time, recalls 416 the situation similarly: "Bill Day was President of the [Washington] State Senate. Magnuson 417 was the Senator from Washington to Federal Government, and he was chair of the 418 Appropriations Committee, powerful. He was a driving force on healthcare. Now this is my 419 personal opinion: the influence that Bill Day had on Senator Magnuson was what drove the 
420 subluxation [focus of the legislation]." ${ }^{, 79}$ Day's perspective, as president of the ICA, was 421 transmitted to the federal legislature through Senators Jackson and Magnuson. It limited 422 chiropractic to the Chicago definition, that is, spinal subluxation relief requiring routine 423 radiography to detect subluxations. Later, in December 1972, Palmer issued a statement 424 disavowing the indiscriminate or routine use of x-rays, but affirming the remainder of the 425 "Chicago definition" of chiropractic. ${ }^{80}$ The Congressional debate on chiropractic was robust. Influential Senator Ted Kennedy opposed including chiropractic in Medicare. He cited cases of chiropractors overstating their abilities to cure serious disease, like cancer, causing patients to avoid seeing medical doctors, with tragic results. But other Senators countered that all health care

430 professions had a small percentage of incompetent or fraudulent practitioners. State regulation, under which licensing/registration boards were established and maintained, was considered adequate to protect the public in those professions and so it should be for chiropractic as well. ${ }^{81} \mathrm{~A}$ few legislators related positive personal experience with a chiropractor, but freedom of choice proved to be a particularly powerful argument regarding healthcare in Congress. Most legislators agreed that the government should not tell citizens that they could not go to a chiropractor instead of a medical doctor if that was their choice. ${ }^{82}$ As sociologist Paul Starr noted, Americans were not willing to submit to the judgement of experts, even in the realm of healthcare. ${ }^{83}$ In fact, there was little evidence of 439 clinical effectiveness on which legislators could base a judgement. There were case anecdotes 440 from the publications of the professional associations and patient testimonials in pamphlets, 441 advertisements, and the letters to Congress. These "success stories" did not contain the level 442 of clinical detail to be publishable in peer-reviewed journals. The first randomized controlled 443 trial of chiropractic was not published until $1990 .{ }^{84}$ The AMA gleaned evidence against 444 chiropractic similarly, from advertisements, anecdotes of patients harmed by chiropractors, 
and by the investigation the AMA did into chiropractic education. ${ }^{85}$ chronic renal disease, disabled people under 65 , a Chiropractic was a very small part. ${ }^{87}$ According to the New York Times (NYT), the House members of the conference committee wanted to delay inclusion of chiropractic in favour of another study of it, but Senate members wanted inclusion. Political "horse trading" ensued and the House yielded to the Senate in exchange for unknown concessions on other matters. In addition, the NYT reported that some sources said Wilbur Mills was annoyed at the AMA, and others indicated he "was tired of standing up almost alone to the pressure of the chiropractors." ${ }^{\text {" }} 8$ The AMA took action to try to neutralize chiropractic's inclusion just before final passage of the bill in Congress by leveraging the idea that "subluxations" were the cause of disease. Medical doctor Stephen Barrett, a leading figure in the fight against chiropractic for decades, wrote to the AMA and suggested that they bring a lawsuit, to "present to the court the impossibility of writing regulations to pay for something that did not exist." But he recalled receiving no response. ${ }^{89}$ Instead, the AMA decided to try to amend the legislation just before passage.

\section{CHIROPRACTORS}

After the House and Senate each pass their versions of a bill, any differences between the two are reconciled in a conference committee. This committee is usually composed of senior members of the House and Senate committees that originally considered the bill.

467 Amendments may be introduced during the conference committee, and after consensus is 468 achieved, the final version of the bill is produced for a vote in both the House and Senate.

469 This is a straight yea or nay vote; no further amendments are allowed on any bill that has 
been through conference committee. If passed, it is sent to the President to sign into law or to

471

472

473

474

475

476

477

478

479

480

481

482

483

484

485

486

487

488

489

490

491

492

493

494 veto.

According to Stephen Barrett, wording from the AMA was inserted during the conference committee. ${ }^{90}$ The specific clause allowed reimbursement to chiropractors only for manual manipulation of spinal subluxations that had been documented by $\mathrm{x}$-ray. No other services were covered, nor was the cost of taking and interpreting the radiographs themselves. Thirty years after the Medicare legislation passed, Barrett recalled the episode: A few weeks after the law was passed, Doyl Taylor, head of the AMA Department of Investigation told me that when chiropractic inclusion appeared inevitable, the "subluxation" language was inserted with the hope of preventing chiropractors from actually being paid. The idea's originator thought that because chiropractic's traditional (metaphysical) "subluxations" were visible only to chiropractors, this provision would sabotage their coverage. ${ }^{91}$

The NYT reported on this amendment made during conference committee, but gives no attribution to any person(s) for the change. ${ }^{92}$ The amendment effectively nullified the practical utility of reimbursement for chiropractic services, and may have been another factor that allowed the House to accede to the inclusion of chiropractic in Medicare. At this point in the Medicare expansion process, any legislator objecting to one element in this massive and popular bill would have had to vote against the entire bill, a politically unwise move. The final bill, including the amendment to chiropractic, passed in both Houses. On 30 October, just a few days before the presidential election of 1972, President Richard M. Nixon signed it into law.

The regulations in the bill had been narrowly formulated so that chiropractors were considered "physicians" for the purpose of radiographically diagnosing and manually treating 
a "subluxation" but not in any wider definition. Specifically, they were not "physicians" under U.S.C. 1395x (s)(3), the part of the law that provided reimbursement for taking x-rays.

497 Reimbursement was also not given for physical exam or other diagnostic procedures. ${ }^{93}$

498 Medicare reimbursed radiographs if a medical doctor ordered them, but the AMA forbade

499 medical doctors and hospitals at the time from accepting referrals from chiropractors. ${ }^{94}$

500 Chiropractors were licensed in all fifty states to take radiographs. But if they performed their own radiography, chiropractors would either have to absorb the cost themselves or ask patients to pay for them. Therefore this legislation caused potential financial harm to patients. Members of the ICA greeted the news of inclusion in Medicare with short-lived jubilation until they realized they would not be reimbursed for the mandated radiography. ${ }^{95}$

505 But within the ACA, it caused an immediate division of opinion. Some members thought Medicare should be abandoned, rather than submitting to the codification in law of such a narrow scope of practice. Joseph Howe was an outspoken ACA member involved with the internal politics of the situation. He assessed the legislative outcome as deleterious and expressed his opinion to the leadership: "I said throw it back. Please don't tie us in to that

510 idea of subluxation being the only thing we do. But they didn't [throw it back]. I think, 511 personally, it's my opinion that Medicare has been a detriment to the profession from the

512 beginning. ${ }^{\circ 96}$ However, the new law brought prestige, legitimation, and gave access to a new 513 cohort of patients, even if chiropractors received inadequate reimbursement for those in that

514 cohort. Ultimately, the ACA leadership decided to accept it, hoping that it might be

515 broadened in the future. ${ }^{97}$ James Winterstein, long-time president of National College of

516 Chiropractic, and an ACA member at the time, acknowledges the dilemma: "I was supportive

517 of inclusion of chiropractic medicine in the Medicare program, but not in the way it was

518 statutorily developed [limiting the scope of practice to spinal subluxation relief and requiring

519 x-rays]. That view was shared by most so called "mixers" of the time. We all thought, 
however that this was the beginning that that as a profession we would be able to change the language to provide a far better functioning statute for the profession and our profession." 98

\section{THE CHIROPRACTIC SOLUTION TO MEDICARE REQUIREMENTS}

Chiropractors had many different definitions of vertebral subluxation, mostly tiny

524

525 changes in position, not acknowledged as real by the medical community and unable to be reliably identified on radiographs by different chiropractors. ${ }^{99}$ The ACA called for a meeting to standardize the definition of radiographically demonstrable subluxations. The meeting took place in Texas in November 1972 and became referred to as the Houston Conference. Within the ACA there existed a group of chiropractors with a special interest in diagnostic imaging. They undertook additional training as well as written and oral certification exams in order to achieve the Diplomate of the American Chiropractic Board of Radiology (DACBR). These "chiropractic radiologists" were called upon at the Houston Conference. ${ }^{100}$

The radiographic demonstration of subluxation was imaginary to at least some involved in the Houston Conference. There were deep misgiving and arguments on the subject. Many of the participants considered the "subluxation" to be a functional lesion of joint motion, rather than a displacement. For these chiropractors, there were no vitalistic implications of "the cause of all disease", but rather "subluxation" was a biomechanical dysfunction amenable to a variety of manual methods, of which chiropractic adjustments were only one. ${ }^{101}$

The new Medicare requirement ran counter to safety guidelines on the use of x-rays in requiring all patients to be radiographed. Joseph Howe wrote: "To demand that there be radiological evidence of vertebral subluxation in order to justify chiropractic treatment is irresponsible. It is totally contradictory to proper radiological health procedure which demands a clinical reason for any application of ionizing radiation to a human being." 102 The X-ray requirement even seemed nonsensical to some legislators. Senator Mike Gravel 
recognized that the AMA had put in place a requirement that ran counter to best medical

546 practice. He wrote that the law "imposes an improper interference with the work and

547 judgment of the Chiropractor. It does not guarantee the health and well-being of the patient;

548 in fact, it may endanger it." ${ }^{103}$ The idea that there was no safe dose of ionizing radiation,

549 called the linear, no-threshold (LNT) model, had been introduced to the world by Herman

550 Muller at his Nobel Prize acceptance speech in 1946. ${ }^{104}$ Although there have been challenges

551 to this model, ${ }^{105}$ and it has never been fully accepted in the chiropractic community, ${ }^{106}$ it

552 became the dominant model in the ensuing decades. By 1956 the National Academy of

553 Sciences (USA) had adopted it. Then, within a few years this paradigm "had transformed

554 governmental regulatory agencies in many countries, including recommendations of the

555 UN." ${ }^{107}$ The National Council on Radiation Protection and Measurements (NCRP) issued radiation protection standards in 1954 , which were revised in 1957 and $1958 .{ }^{108}$ The 1958 edition introduced the risk/benefit calculation to the application of ionizing radiation, which later evolved into the ALARA (As Low As Reasonably Achievable) principle. ${ }^{109}$ Despite this, formal training in radiation safety was spotty in medicine. ${ }^{110}$ However, by the time of

560 the Medicare expansion in 1972 the potential hazards of x-rays, even at low, diagnostic doses, had been well-publicized, and should have been known to chiropractors, physicians, and legislators involved in the issue. There is evidence that this in fact was known in the

563 medical community; a letter from the Lehigh Valley Committee Against Health Fraud, a

564 group of health professionals including Stephen Barrett, to the United States Senate Finance

565 Committee stated that they considered chiropractic x-rays to be "window dressing" and "a 566 radiation hazard."111 This statement acknowledges both the understanding of the potential

567 danger of low levels of ionizing radiation, as well as the fact that x-rays should not be used in 568 the absence of clinical justification. In light of the comments above, key figures in both the 569 medical and chiropractic communities did understand the safety issue and spoke out about it. 
It therefore seems more likely that the issue was ignored rather than unknown. and DACBR James Cox recalled: "While I felt apprehension about taking the program [the

574 limited scope of practice as defined in Medicare] as it was... the consensus out of my

575 profession and out of the ACA was that it was the proper step to take, so I supported that, 576 because that's what my profession wanted to do." 112 The DACBR solution was to use various medically recognized vertebral displacements and postural changes like spondylolisthesis and scoliosis, calling them "subluxation" purely to meet the Medicare requirement of radiographically documenting a positional change in one or more vertebrae in order to justify reimbursement for treatment. ${ }^{113}$ James Winterstein remembered: "ACA developed a "Medicare Manual" [the Basic Chiropractic Procedural Manual] and Joe Howe and I wrote the section on radiography mostly at the kitchen table at my home office in West Chicago, Illinois. In the manual we defined "subluxation" and showed examples and drew radiographs from my practice as evidence for the various types of subluxation." ${ }^{114}$ Joseph

585 Howe added: "We came up with seventeen classifications, which was just foolishness, 586 frankly." 115 These were political, not clinical definitions of subluxation. The DACBRs and 587 likely the ACA leadership knew that their "subluxations" were not the ultimate cause of 588 disease. Irradiating patients in order to document these subluxations ran counter to the 589 individual risk/benefit appraisal that should have been performed on each patient when 590 considering the use of x-rays. But, chiropractors were then able to document their "lesion" as 591 required by the law. The ACA published the "subluxations" in the Manual as well as in other 592 media. ${ }^{116}$ They also paid for several members to travel around the country giving 593 presentations disseminating the system. ${ }^{117}$ Some ACA members like Joseph Howe were 594 uncomfortable with the situation, but participated nonetheless: "Jim Winterstein and I 
595 developed slides of all those things. We made it up in a carousel [for slide presentation] and we set out, a group of us, to teach that across the world. Something I have regretted ever

597 since." ${ }^{118}$ Chiropractors had found a way to make the legislation workable, although they

598 knew it was ethically questionable.

Another potential harm to patients never mentioned by either side is the fact that in a proportion results from any type of diagnostic study there will be an anomalous result, often a

601 false-positive, that requires further investigation. This often causes anxiety and further cost for patients needing additional studies, as was noted in the debate around mammography for breast cancer screening. ${ }^{119}$ Even under these dubious circumstances, inclusion in Medicare was a significant achievement for chiropractic. In 1972, few inroads had been made towards government reimbursement for chiropractic services anywhere in the world, nor were there chiropractors on staff in government hospitals. This event influenced contemporaneous registration and reimbursement inquiries on chiropractic in several countries, but at least one, New Zealand, stated that they "did not consider the formula applied in USA to be appropriate for their

610 area." 120 The places where chiropractic has had the best success with integration into 611 government provision of healthcare are Denmark, Switzerland, and Canada. In those

612 countries, chiropractors in subsequent decades decided largely to abandon traditional 613 paradigms. Consequently, they are reimbursed equivalently with other practitioners. In 614 addition, those countries, and particularly Alberta in Canada, have the highest utilization rates 615 for chiropractic, about twice that of other areas. ${ }^{121}$ The first government investigation of cost616 effectiveness for chiropractic was a study in Canada on low-back pain in 1993; it reported 617 positive findings. ${ }^{122}$ However, evidence for improved patient outcomes from chiropractic 618 treatment based on the radiographic demonstration of chiropractic subluxations or postural 619 changes has never been documented in a peer-reviewed, indexed journal. 
General Accounting Office, a non-partisan bureau of analysts for the U.S. government, also submitted the following statement regarding the chiropractic $\mathrm{x}$-ray requirement: "Since the $\mathrm{x}$ ray serves no medical benefit... the patient is unnecessarily exposed to hazardous radiation solely to fulfil an administrative requirement. The cost of the x-ray can be an expensive burden to the Medicare beneficiary as well."123 But, this attempt to change the legislation failed. The x-ray requirement was not removed from the Medicare regulations until 1 January 2000, when components of the Balanced Budget Act of 1997 were enacted. ${ }^{124}$ Chiropractors remained reimbursable only for manual manipulation to remove spinal "subluxations," but the subluxations could be documented by means other than x-ray. ${ }^{125}$

\section{CONCLUSION} that represent registered healthcare practitioners. Although the associations are bound to protect and promote the interests of their members, not the public, the boards of professional associations are largely comprised of professionals who are ethically bound to protect the

637 public. ${ }^{126}$ The events described herein demonstrate that the focus by both organized chiropractic and organized medicine was not solely on public interest but rather more heavily on the interests of their respective professions. It shows the distortion of perspective that may

640 result during a "turf war", in which two professions fight for, inter alia, public status and 641 healthcare dollars, with inadequate consideration of the patients receiving their services.

643 its position as protectors of the public from the "rabid dogs" and "killers" that were

644 chiropractors. ${ }^{127}$ Biggs portrayed this episode as a critical junction in the legitimization and 
economic survival of chiropractic as a profession. Recognition under Medicare raised

chiropractic's status and failure to be included would have meant that the cohort of Medicare

647 patients may have gone on to receive services from other practitioners, like

648 physiotherapists. ${ }^{128}$ But it had negative effects for the profession, as well. It reinforced the

649 traditional chiropractic belief system and it did not conform to radiation safety guidelines. ${ }^{129}$

All the professional associations involved in this battle lost sight of the civic duty that comes with being a healthcare provider. The AMA decided to bet that the altering the

Medicare legislation would make it useless to chiropractors, but they lost the wager because chiropractors found a way to work within the limits of the legislation. The AMA did not adequately consider the consequences in the event that they lost.

Within chiropractic, the ICA had long promoted the use of x-rays for subluxation analysis, although there was, and still is, little evidence to support that belief. This meant that the scope of the legislation posed no ethical problem for them, but they were unhappy about the lack of reimbursement. Some chiropractors in the ACA, though, compromised their values on requiring clinical justification for the use of ionising radiation. The ACA advocated

660 for a system that they did not really believe in so that they could gain the political "win" of becoming providers for Medicare patients.

662

For its part, the state took the expedient course. Legislators responded to the weight of

663 popularity of chiropractic, rather than clinical evidence for its effectiveness. They also

664 responded to strong emotions attached to the patriotic argument of freedom of choice. At

665 least one Senator has indicated that the change requiring radiography of all chiropractic

666 Medicare patients inserted into the conference committee report was considered insignificant

667 in the scheme of the overall bill. ${ }^{130}$ Few Senators or Representatives would have been willing 668 to vote against Medicare expansion because of a change to one element in one part of the bill, 669 a large and popular piece of legislation. 
671 and the state took a course of compromise, trying to please everyone and ending up pleasing

672 no one. The damage from decades of x-rays being unjustifiably used on the Medicare

673 population has not been quantified, but is certain to exist. It manifested in several ways: in

674 potential damage to patients' health, the financial cost of $x$-rays, and by causing stress as well

675 as further diagnostic testing for patients with false-positive x-ray results. All parties,

676 including most importantly patients, would have benefitted if those involved in the battle for

677 chiropractic inclusion in Medicare had looked to evidence-based practice paradigms and

678 patient-focused care as their main objectives.

679

$680 \quad$ Notes

681

${ }^{1}$ This is actually not word for word in the Oath, although the sentiment is. The phrase is: "I will keep them [the sick] from harm and injustice.” Michael North [translator], "Greek Medicine - Hippocratic Oath,” National Library of Medicine, 2002, available at: https://www.nlm.nih.gov/hmd/greek/greek_oath.html, (accessed 30 April 2019).

${ }^{2}$ J. Keith Simpson, Barrett Losco, and Kenneth J. Young, "Development of the Murdoch Chiropractic Graduate Pledge,” Journal of Chiropractic Education, 2010, 24, 175-86.

${ }^{3}$ Richard D. Lyons, 'Nixon Signs \$5-Billion Bill Expanding Social Security', New York Times, 31 October 1972, 1.

${ }^{4}$ Rosemary A. Stevens, "History and Health Policy in the United States: The Making of a Health Care Industry, 1948-2008," Social History of Medicine, 2008, 21, 461-83; Robin Bunton and Roger Burrows, "Consumption and Health in the 'Epidemiological Clinic' of Late Modern Medicine," in The Sociology of Health Promotion: Critical Analyses of Consumption, Lifestyle and Risk, ed. Robin Bunton, Sarah Nettleton, and Roger Burrows 
(London: Routledge, 1995); Rene I. Jahiel, "Health Care System of the United States and Its Priorities: History and Countries," Croatian Medical Journal, 1998, 39, 3-10; Miriam J. Laugesen, Fixing Medical Prices: How Physicians Are Paid (Cambridge, MA: Harvard University Press, 2016), 69.

${ }^{5}$ Jenny M. Lewis and Mark Considine, "Medicine, Economics and Agenda-Setting," Social Science \& Medicine, 1999, 48, 393-405.

${ }^{6}$ Charles Vincent, "Medical Harm: A Brief History," in Charles Vincent, Patient Safety, 2 ${ }^{\text {nd }}$ ed. (John Wiley \& Sons, Ltd, 2010), 3-8.

${ }^{7}$ Matthew K. Wynia, “The Short History and Tenuous Future of Medical Professionalism: The Erosion of Medicine's Social Contract," Perspectives in Biology and Medicine, 2008, 51, $565-78$.

${ }^{8}$ American Medical Association, Code of Ethics of the American Medical Association, (Philadelphia: American Medical Association, 1848).

${ }^{9}$ Eliot Freidson, Professional Dominance: The Social Structure of Medical Care (New York: Atherton Press, 1970), 18; Eliot Friedson, “Theory of Professionalism: Method and Substance," International Review of Sociology, 9, 117-29.

${ }^{10}$ Wynia, "Medical Professionalism.”

${ }^{11}$ Abraham Flexner, Medical Education in the United States and Canada: A Report to the Carnegie Foundation for the Advancement of Teaching: Bulletin No. 4 (New York: The Carnegie Foundation for the Advancement of Teaching, 1910); American Medical Association, Nostrums and Quackery (Chicago, Il: American Medical Association, 1872); Anon., "Chiropractors -- Healers or Quacks? Part 1: The 80-Year War with Science," Consumer Reports, 1975, 40, 542-47; Terri A. Winnick, "From Quackery to Complementary Medicine: The American Medical Profession Confronts Alternative Therapies," Social Problems, 2005, 52, 38-61; James Harvey Young and Stephen Barrett, “A Historian's View 
of Quackery in 1974,” Quackwatch (blog), 2016, available at:

https://www.quackwatch.org/13Hx/humbug.html, (accessed 30 November 2017).

12 James G. Burrow, Organized Medicine in the Progressive Era: The Move Toward

Monopoly (Baltimore, MD: Johns Hopkins University, 1977), 58.

${ }^{13}$ Tracey L. Adams, "Professional Regulation in Canada: Past and Present," Canadian Issues, 2007, 14-16.

${ }^{14}$ Hans A. Baer, “The American Dominative Medical System as a Reflection of Social Relations in the Larger Society," Social Science \& Medicine, 1989, 28, 1103-12.

${ }^{15}$ Wynia, "Medical Professionalism."

${ }^{16}$ James C. Whorton, Nature Cures: The History of Alternative Medicine in America (Oxford: Oxford University Press, 2002), 239-40; Norman Gevitz, The D.O.s: Osteopathic Medicine in America (Baltimore: Johns Hopkins University Press, 1982), 145.

${ }^{17}$ Susan Getzendanner, "Chester A. Wilk V. American Medical Association,” in 76 C 3777, ed. United States Court of Appeals Seventh Circuit (1987).

${ }^{18}$ William Trever, In the Public Interest (Los Angeles, CA: unknown, 1972); Chester Wilk, "Chiropractic in Medicare," Chiropractic Speaks Out: A Reply to Medical Propaganda, Bigotry, And Ignorance, (Park Ridge, IL: Chester Wilk, 1973), 74-82.

${ }^{19}$ Dennis Peterson and Glenda Wiese, Chiropractic, an Illustrated History (St. Louis: Mosby Year-Book, 1995); Holly Folk, The Religion of Chiropractic: Populist Healing from the American Heartland (North Carolina: University of North Carolina Press, 2017); J. Stuart Moore, Chiropractic in America (Baltimore, MD: Johns Hopkins University Press, 1993), 115, 129-30, 144; Walter I. Wardwell, Chiropractic : History and Evolution of a New Profession (St. Louis: Mosby-Year Book, 1992); Susan L. Smith-Cunnien, “The campaign against chiropractic, 1961 - 1976: Chiropractic as enemy," A Profession of One's Own, (Lanham, MD: University Press of America, 1998), 85-113. 
${ }^{20}$ Daniel David Palmer, The Chiropractor's Adjuster: Textbook of the Science, Art and Philosophy of Chiropractic for Students and Practitioners, (Portland, OR: Portland Printing House Company, 1910), 96.

${ }^{21}$ Bartlett Joshua Palmer, Our Masterpiece (Davenport, IA: Palmer School of Chiropractic, 1966); Palmer, The Chiropractor's Adjuster, 14-16.

${ }^{22}$ Peterson and Wiese, Chiropractic, an Illustrated History, 180.

${ }^{23}$ Federation of Chiropractic Licensing Boards, History of Regulation, available at: http://directory.fclb.org/About/HistoryofRegulation.aspx, (accessed 24 April 2019).

${ }^{24}$ Council on Chiropractic Education, "History," available at: http://www.cceusa.org/history.html, (accessed 24 April 2019).

${ }^{25}$ Tracey L. Adams, “Chiropody/Podiatry: Interprovincial Differences in Profession Formation," Canadian Bulletin of Medical History = Bulletin Canadien d'Histoire de la Médecine, 2017, 34, 364-92; Anne Taylor Kirschmann, "Making Friends for 'Pure' Homeopathy: Hahnemannians and the Twentieth-Century Preservation and Transformation of Homeopathy," in The Politics of Healing: Histories of Alternative Medicine in TwentiethCentury North America, Robert D. Johnson, ed., (New York: Routledge, 2004), 29-42. ${ }^{26}$ Kenneth J. Young, "Evaluation of publicly available documents to trace chiropractic technique systems that advocate radiography for subluxation analysis: a proposed genealogy", Journal of Chiropractic Humanities, 2014, 21, 1, 1-24.

${ }^{27}$ Dana J. Lawrence and William C. Meeker, "Chiropractic and Cam Utilization: A Descriptive Review," Chiropractic \& Osteopathy, 2007, 15, 2; Peter J. H. Beliveau et al., "The Chiropractic Profession: A Scoping Review of Utilization Rates, Reasons for Seeking Care, Patient Profiles, and Care Provided," Chiropractic and Manual Therapies, 2017, 25, 35. 
${ }^{28}$ Trever, In the Public Interest; Wilk, Chiropractic Speaks Out; H. Thomas Ballantine, Jr., "Will the Delivery of Health Care Be Improved by the Use of Chiropractic Services," New England Journal of Medicine, 1972, 286, 237-42; Anon., "Reports and Comments," Medical Care and Research Review, 1970, 27, 310-23; "A Call to Arms," Journal of the American Medical Association, 1971, 217, 959; "In the Wisdom of Congress," Journal of the American Medical Association, 1970, 211, 1002-3.

${ }^{29}$ American Medical Association Department of Investigation, Chiropractic: The Unscientific Cult (Chicago, 1966), 3.

${ }^{30}$ American Medical Association Department of Investigation, Chiropractic: The Unscientific Cult, 3.

${ }^{31}$ H. Doyl Taylor, Quackery Workshop (Muncie, Indiana: Ball State University, 1967), Audio recording 02 August 1967, available at: http://libx.bsu.edu/cdm/singleitem/collection/HistAudioRe/id/213/rec/1, (accessed 20 September 2017).

${ }^{32}$ Yvonne Villanueva-Russell, "Chiropractors as folk devils: published and unpublished news coverage of a moral panic”, Deviant Behavior, 2009, 30, 2, 175-200; Susan L. SmithCunnien, A Profession of One's Own: Organized Medicine's Opposition to Chiropractic (Lanham: University Press of America, 1998), 87.

${ }^{33}$ William Trever, In the Public Interest (Los Angeles: Scriptures Unlimited, 1972), 25-26, $61 ;$

${ }^{34}$ Joseph A. Sabatier et al., Memorandum, in Trever, In the Public Interest, notes for chapter 2.

35 Trever, In the Public Interest, 2.

${ }^{36}$ Trever, In the Public Interest, 2. 
${ }^{37}$ American Medical Association Department of Investigation, Chiropractic: The Unscientific Cult, 9-12.

${ }^{38}$ H. Doyl Taylor, Unit Plan for the AMA Committee on Quackery (unknown, May 17, 1974), 1.

${ }^{39}$ Taylor, Unit Plan, 1.

${ }^{40}$ Taylor, Unit Plan, 3.

${ }^{41}$ This opposition by working-class groups sets the fight for American Medicare coverage apart from the fight for Canadian Medicare coverage. Support from working-class organizations was crucial to the success of chiropractic in Ontario. (Catherine L. Biggs, No Bones About Chiropractic? The Quest for Legitimacy by the Ontario Chiropractic Profession, 1895 to 1985, (Ph.D., University of Toronto, 1990), 348-350.

${ }^{42}$ Taylor, Unit, 5; AFL-CIO, “AFL-CIO Fact Sheet on Chiropractic," Journal of the American Medical Association, 1970, 214, 1095-6.

${ }^{43}$ Theodore R. Marmor, The Politics of Medicare, $2^{\text {nd }}$ ed., (Hawthorne, NY: Aldine Transaction, 2000), 46.

${ }^{44}$ Carl F. Ameringer, The Health Care Revolution: From Medical Monopoly to Market Competition, (Berkeley: University of California Press, 2008), 55.

${ }^{45}$ Marmor, The Politics of Medicare, 77.

${ }^{46}$ Social Security Administration, The History of Medicare, available at: https://www.ssa.gov/history/tally65.html, (accessed October 30, 2016); Centers for Medicare \& Medicaid Services, "Medicare and Medicaid: Keeping Americans healthy for 50 years," The Medicare Blog, available at: https://blog.medicare.gov/2015/07/27/medicare-andmedicaid-50-year-anniversary/ (accessed 01 November 2016); Karen Davis and Roger Reynolds, "The impact of Medicare and Medicaid on access to medical care," in Richard N. 
Rosett (ed.), The Role of Health Insurance in the Health Services Sector, (Washington, D.C.: National Bureau of Economic Research, 1976), 391-436.

${ }^{47}$ Mollyanne Brodie, Elizabeth C. Hamel, Mira Norton, "Medicare as reflected in public opinion", Journal of the Amererican Society on Aging, 2015, 39, 2, 134-41.

${ }^{48}$ Richard E. Vincent, telephone interview with the author, January 21, 2016.

${ }^{49}$ Wardwell, Chiropractic, 164.

${ }^{50}$ Wardwell, Chiropractic, 165.

${ }^{51}$ Biggs, No Bones About Chiropractic, 357-365.

${ }^{52}$ Cohen, Independent practitioners under Medicare, 68.

${ }^{53}$ Wilbur J. Cohen, Independent Practitioners under Medicare: A Report to Congress (1968), available at: https://www.chirobase.org/05RB/HEW/hew00c.html, (accessed 01 May 2019). I could not access the original documents, but found these reproductions and have no reason to doubt their veracity.

${ }^{54}$ James Cox, interview with the author, 24 October 2015, Minneapolis, USA.

${ }^{55}$ Wardwell, Chiropractic, 166.

${ }^{56}$ Cohen, Independent Practitioners Under Medicare, 75.

${ }^{57}$ Wardwell, Chiropractic, 166; Cohen, Independent Practitioners Under Medicare, 75.

${ }^{58}$ Palmer College of Chiropractic, "Palmer: an official statement of policy," The Digest of Chiropractic Economics, (November/December 1972), 48-49.

${ }^{59}$ International Chiropractors Association, "X-ray training vital to chiropractor," International Review of Chiropractic, 1970 Pre-convention edition of the quarterly review, 5. ${ }^{60}$ Leon Coelho, R., "If Spinography Is Dead, So Is Chiropractic," International Review of Chiropractic, 1977, 8-11.

${ }^{61}$ Joseph W. Howe, "Letter to the Editor,” Digest of Chiropractic Economics, July/August 1971,4 
${ }^{62}$ Joseph W. Howe, "Some considerations in spinal x-ray interpretation", Digest of Chiropractic Economics, September/October 1970, Supplement, B-C.

${ }^{63}$ Hoyt B. Duke, "Statement before National Congress of Chiropractic State Presidents, 5 June 1971”, The ACA Journal of Chiropractic, July 1971, 15-20.

${ }^{64}$ Cohen, Independent Practitioners Under Medicare; United States Senate, "Proceedings and debates of the $92^{\text {nd }}$ Congress, Second Session," Congressional Record, (Washington, DC, October 5, 1972), 118, 159.

${ }^{65}$ United States Senate, “92 ${ }^{\text {nd }}$ Congress, Second Session,” 118, 159.

66 “HEW Response to Chiropractic 'White Paper' on the Report 'Independent Practitioners under Medicare'," available at: https://www.chirobase.org/05RB/HEW/wp01.html, (accessed 01 May 2019). Again, I could not access original documents, but found this reproduction. ${ }^{67}$ Duke, "Statement," 15-20.

${ }^{68}$ W. Luckey, "Leaders to meet at Parker seminar," Digest of Chiropractic Economics, (January-February 1970), 4.

${ }^{69}$ Hoyt B. Duke, “Argues for Chiropractic in Medicare Program,” Des Moines Register, 08 December, 1970, 6; American Chiropractic Association, 'Freedom of choice under Medicare: how to get it!," Corbin Times Tribune, 31 August, 1971, 7.

${ }^{70}$ Seymour Martin Lipset, American Exceptionalism: A Double-Edged Sword, (New York: W.W. Norton, 1996), 19.

${ }^{71}$ G.D. Parrott, “By virtue of truth”, The ACA Journal of Chiropractic, July 1970, 35-41; Frank A. Rogers, "The American Medical Association: Yesterday, Today, and Tomorrow," The Journal of the Louisiana State Medical Society, 1981, 133, 129-35.

${ }^{72}$ William S. Day, “ICA elects Dr. William S. Day President 1970-71,” The Digest of Chiropractic Economics, (September/October 1970), Supplement, H-51. 
${ }^{73}$ Three sources stated three different numbers; Fineberg said one million, Taylor three million and Wardwell twelve million. H.I. Fineberg, "Reports of Officers: Chiropractic and Medicare", New York State Journal of Medicine, (January 1, 1971), 79-80; Taylor, Unit Plan, 3; Wardwell, Chiropractic, 166.

${ }^{74}$ United States Senate, "92 ${ }^{\text {nd }}$ Congress, Second Session,” $118,159$.

${ }^{75}$ Legislative Information Center, Members of the Washington State Legislature 1889-2011 (Olympia, WA 2011).

${ }^{76}$ Day, "ICA elects," H-51.

${ }^{77}$ United States Senate "Hearings before the Committee on Finance, $91{ }^{\text {st }}$ Congress, 2 nd Session on H.R. 17550”, Social Security Amendments of 1970 (Washington, DC 1970), 569.

${ }^{78}$ Steve Renner, email to the author, 18 February 2016.

${ }^{79}$ Vincent, interview.

${ }^{80}$ Palmer College of Chiropractic, "Palmer: an official statement of policy," The Digest of Chiropractic Economics (November/December 1972), 48-49.

${ }^{81}$ United States Senate, “92 ${ }^{\text {nd }}$ Congress, Second Session,” 118, 159. In reality, licensing/registration boards have little scope to act on their own and usually require a complaint to be made by a member of the public or of the profession. They are reactive rather than proactive, so someone has to be negatively affected by the actions of a healthcare provider before a licensing/registration board acts.

${ }^{82}$ Ameringer, The Health Care Revolution, 55-58; United States Senate, "92 ${ }^{\text {nd }}$ Congress, Second Session," 118, 159; Peter Morrison, "Adjusting the Role of Chiropractors in the United States: Why Narrowing Chiropractor Scope of Practice Statutes Will Protect Patients," Health Matrix, 2009, 19, 2, 493-537.

${ }^{83}$ Paul Starr, The Social Tranformation of American Medicine (Cambridge, MA: Basic Books, 1982), 17. 
${ }^{84}$ T. W. Meade et al., "Low Back Pain of Mechanical Origin: Randomised Comparison of Chiropractic and Hospital Outpatient Treatment," BMJ : British Medical Journal, 1990, 300, 1431.

${ }^{85}$ AMA Department of Investigation, Chiropractic: The Unscientific Cult, (Chicago: American Medical Association, 1966).

${ }^{86}$ Blumenfield and Stevens, "How to play the Medicare game," Digest of Chiropractic Economics, September/October 1974, 76-77.

${ }^{87}$ Robert M. Ball, "Social Security amendments of 1972: summary and legislative history," in Bulletin (Washington, D.C.: Social Security Administration, 1973).

${ }^{88}$ Richard D. Lyons, "7 Years of Lobbying Finally Brings Chiropractic under the Umbrella of Medicare," New York Times, 19 November 1972, 55.

${ }^{89}$ Stephen Barrett, email to the author, 02 May 2019.

${ }^{90}$ Stephen Barrett, "Medicare Chiropractic Billing Policies Revised,” (blog, 02 October 2004), available at: https://www.chirobase.org/19Insurance/mc2004.html, (accessed 25 August 2016).

${ }^{91}$ Barrett, Medicare Chiropractic Billing Policies. I emailed Stephen Barrett to find out if there was anyone else who might know who had the idea for the x-ray requirement, and who made the decision to try to get it into the bill. He responded by email on 05 May 2019, stating that the youngest member of the Committee on Quackery died in 2017 and he thought that they were all now dead.

${ }^{92}$ Lyons, "7 Years," 55.

${ }^{93}$ Public Law 92-603: Social Security Amendments of 1972; Social Security Administration, "Medicare final regulations published", Federal Register, 39, 155 (August 9, 1974), 1-3.

${ }^{94}$ U.S. Court of Appeals for the Seventh Circuit, (07 February 1990), Chester A. Wilk, James W. Bryden, Patricia B. Arthur, Michael D. Pedigo v. American Medical Association, 
available at: http://law.justia.com/cases/federal/appellate-courts/F2/895/352/46788/ (accessed

December 13, 2016).

${ }^{95}$ M. Butler, “Congress passes chiropractic Medicare', Today's Chiropractic

(October/November 1972), 20.

${ }^{96}$ Joseph W. Howe, interview with the author 25 October 2015, Minneapolis, USA.

${ }^{97}$ Cox, interview.

${ }^{98}$ James Winterstein, email to the author, 17 November 2015.

${ }^{99}$ United States Senate "Hearings before the Committee on Finance, $91^{\text {st }}$ Congress, $2^{\text {nd }}$

Session on H.R. 17550", Social Security Amendments of 1970 (Washington, DC 1970), 454.

${ }^{100}$ Joseph W. Howe, "A Contemporary Perspective on Chiropractic and the Concept of Subluxation," The ACA Journal of Chiropractic, 1976, 10, S165-S69.

${ }^{101}$ Howe, interview.

${ }^{102}$ Joseph W. Howe, "The Chiropractic Concept of Subluxation and its Roentgenological Manifestations", Journal of Clinical Chiropractic, 1973, 1, 1, 64-70.

${ }^{103}$ Mike Gravel, "Chiropractic Article”, International Review of Chiropractic, October 1973, $26,5,4,20$.

${ }^{104}$ Hermann J. Muller, "Nobel Lecture," paper presented at the Nobel Prize Ceremony, Stockholm, Sweden, 1946.

${ }^{105}$ Edward J. Calabrese, "Muller's Nobel Lecture on Dose-Response for Ionizing Radiation: Ideology or Science?," Archives of Toxicology. Archiv für Toxikologie, 2011, 85, 1495-8. ${ }^{106}$ Paul A. Oakley and Deed E. Harrison, "Radiogenic Cancer Risks from Chiropractic XRays Are Zero: 10 Reasons to Take Routine Radiographs in Clinical Practice," Annals of Vertebral Subluxation Research, 2018, 20, 48-56.

${ }^{107}$ Calabrese, 'Muller's Nobel Lecture." 
${ }^{108}$ National Council on Radiation Protection and Measurements, "Basic Radiation Protection Criteria: Recommendations," (NCRP: Washington, D.C.,1971).

${ }^{109}$ A. Brodsky et al., "History of the Medical Uses of Radiation: Regulatory and Voluntary Standards of Protection," Health Physics, 1995, 69, 783-823.

${ }^{110}$ J. Samuel Walker, Permissible Dose : A History of Radiation Protection in the Twentieth Century (Berkeley: University of California Press, 2000), 81-82.

${ }^{111}$ H. William Gross, Letter to the U.S. Senate Finance Committee from the Lehigh Valley Committee Against Health Fraud, 15 February 1972.

${ }^{112}$ Cox, interview.

${ }^{113}$ Cox, interview.

${ }^{114}$ Winterstein, email.

115 Howe, "Chiropractic and Medicare."

${ }^{116}$ Joseph W. Howe and James Winterstein, "Radiologic manifestations of spinal subluxations", in R.C. Schafer, (ed.) Basic Chiropractic Procedural Manual, 1st Edition (Arlington, VA: American Chiropractic Association, 1973, VI-1-40.

${ }^{117}$ Blumenfield and Stevens, "How to play the Medicare game"; Cox, interview.

${ }^{118}$ Howe, "Chiropractic and Medicare."

${ }^{119}$ Barron H. Lerner, “To See Today with the Eyes of Tomorrow: A History of Screening Mammography," Canadian Bulletin of Medical History = Bulletin Canadien d'Histoire de la Médecine, 2003, 20, 299-321.

${ }^{120}$ J. C. Teece, H.C. Sheath, and C.P. Hudson, Report of Committee of Inquiry into the Question of the Registration of Chiropractors, (Sydney: State Government of New South Wales, 1973); John M. J. Jens et al., Victoria: Report Upon Osteopathy, Chiropractic, Naturopathy, (Melbourne: Joint Select Committee [Osteopathy, Chiropractic and 
Naturopathy], 1975); B.D. Inglis, Betty Fraser, and B.R. Penfold, Chiropractic in New

Zealand: Report of the Commission of Inquiry, (Auckland: House of Representatives, 1979).

${ }^{121}$ Chad Kulak, "Market Research Shows Positive News” InTouch, February 2017, 1-3; Dana

J. Lawrence and William C. Meeker, "Chiropractic and Cam Utilization: A Descriptive

Review," Chiropractic and Osteopathy, 2007, 15, 2; Barry Kim Humphreys et al., "Are

Swiss Chiropractors Different Than Other Chiropractors? Results of the Job Analysis Survey

2009," Journal of Manipulative and Physiological Therapeutics, 2010, 33, 519-35; Barry

Kim Humphreys and Cynthia K. Peterson, "The Swiss Master in Chiropractic Medicine

Curriculum: Preparing Graduates to Work Together with Medicine to Improve Patient Care,"

Journal of Chiropractic Humanities, 2016, 23, 53-60.

${ }^{122}$ Pran Manga et al., "The Effectiveness and Cost-Effectiveness of Chiropractic

Management of Low-Back Pain," (Ontario: Ontario Ministry of Health, 1993).

${ }^{123}$ United States Congress, Unnecessary Exposure to Radiation from Medical and Dental X-

Rays Hearings before the Subcommittee on Oversight and Investigations of the Committee on Interstate and Foreign Commerce, House of Representatives, Ninety-Sixth Congress, First Session, July 24 and 31, 1979, Serial - House, Committee on Interstate and Foreign Commerce, No. 96-46 (Washington: U.S. Govt. Print. Off., 1979).

${ }^{124}$ June Gibbs Brown, Chiropractic Care: Controls Used by Medicare, Medicaid, and Other Payers, (Atlanta: Office of the Inspector General, Department of Health and Human Services, United States, 1998).

${ }^{125}$ Department of Health and Human Services Office of the Inspector General, Chiropractic Services in the Medicare Program: Patient Vulnerability Analysis, 2005, available at: http://oig.hhs.gov/oei/reports/oei-09-02-00530.pdf, (accessed December 15, 2016). 
${ }^{126}$ Simpson, Losco, and Young, "Development of the Murdoch Chiropractic Graduate Pledge"; Marshall Deltoff, "One Profession--One Oath? A Survey of the Disparity of the Chiropractic Oath," Chiropractic History, 1988, 8, 21-25.

${ }^{127}$ Joseph A. Sabatier, “Chiropractors," paper presented at the Chiropractic Workshop, Lansing, MI, 10 May 1973.

${ }^{128}$ Biggs, "No Bones About Chiropractic?," 324.

${ }^{129}$ Howe, “The Chiropractic Concept of Subluxation,' 64-70; E.S. Credlin, “A scientific test of the chiropractic theory: the first experimental study of the basis of chiropractic demonstrates that it is erroneous," American Scientist, 1973, 61, 5, 574-80.

${ }^{130}$ Gravel, "Chiropractic Article,” 20. 